\title{
PINTURA E PENSAMENTO MATEMÁTICO NA OBRA DE PIERO DELLA FRANCESCA
}

\author{
Annie Simões Rozestraten Furlan \\ Docente do Centro Universitário Moura Lacerda e FAAP -Ribeirão Preto
}

\section{Introdução:}

Piero della Francesca (1410/20-1492) é um dos mais importantes artistas do Quatrocentos italiano, sua obra desenvolve-se entre a década de 40 e meados da década de 70. Paralelamente ao seu trabalho como pintor, escreve três tratados matemáticos, sendo um deles relacionado à pintura. Trata-se de De prospectiva pingendi, onde desenvolve, em três partes, uma série de demonstrações de projeções baseadas na geometria e na perspectiva. Como este trabalho se relaciona com sua obra através de interpretações de importantes autores que se dedicaram a Piero della Francesca é uma questão que se coloca, e, outra, é como o pensamento matemático permeia as diferentes leituras destes historiadores e comentadores do trabalho de Piero. Não é raro perceber, entre estas abordagens, um distanciamento da relação entre a pintura e o De prospectiva pingendi.

\section{O De prospectiva pingendi ${ }^{1}$}

Cronologicamente situado entre Della Pittura, de Alberti, e Traité de la peinture, de Leonardo da Vinci, De prospectiva pingendi é dividido em três livros. O primeiro livro é centrado em figuras de geometria plana. A segunda parte trata dos volumes de corpos regulares, ou poliedros. E, o terceiro livro onde Piero se dedica a corpos mais complexos, entre eles, colunas, algumas construções arquitetônicas, e especialmente, dedica vários exemplos às projeções de cabeças humanas.

Piero, no início do primeiro livro, afirma que a pintura compreende, disegno, commensuratio e colorare, o desenho como "perfis e contornos que delimitam cada coisa", commensuratio, "a colocação em seus lugares e nas suas respectivas proporções de seus perfis e de seus

\footnotetext{
A data precisa do tratado não é sabida, no entanto foi dedicado a Guidobaldo de Montefeltro e dado ao seu genitor, Federico de Montefeltro, que faleceu em 1482, daí ser o tratado anterior a 1482 (Clergeau,1992,p.73). Longhi acredita que o tratado seja do fim da década de 60, (Longhi,1989,p.201).
} 
contornos". Quanto ao colorir, "atribuição de cores, tais como se apresentam nas coisas, claras e escuras conforme a luz que as faz variar"'(della Francesca,1998,p.40). O colorir, esta terceira parte da pintura, não faz parte dos escritos teóricos de Piero, pois, como ele mesmo escreve, "trataremos desta parte que podemos demonstrar com as linhas, os ângulos e as proporções, tratando de pontos, de linhas, de superfícies e de corpos sólidos"(Ibid.).

Piero delimita um, entre os três aspectos que compõem a pintura, a commensuratio, mais especificamente a "prospectiva", parte que compõe com o desenho, e que não se pode desligar da commensuratio. A palavra prospectiva apresenta uma diferença com perspectiva, a primeira (pro-spettare) designa ver adiante, olhar o que está a frente, enquanto que perspectiva, (perspettare) designa ver através de, ou a "metáfora da janela" de Alberti.

Inicia o terceiro livro com uma das frases mais citadas em estudos sobre o trabalho de Piero, que é a seguinte: "Muitos pintores condenam a perspectiva porque eles não entendem a potência das linhas e dos ângulos que são produzidos por ela e com as quais cada contorno e cada traço se encontram descritos segundo as regras da "comensuração" (della Francesca,1998,p.145).

\section{De prospectiva pingendi e suas ligações com a pintura de Piero della Francesca}

Marie Françoise Clergeau, em Du De prospectiva pingendi à la peinture de Piero: Quel lien? (in Emiliani, Curzi, 1992), atribui ao tratado o caráter de preenchimento de uma necessidade da prática da pintura. Em seu texto, busca exemplos de partes do tratado, principalmente cabeças, que podem ser reconhecidas nos afrescos de Arezzo, (anteriores a 1466, Clergeau, in Emiliani, Curzi,1996, p.70). "O canteiro de Arezzo nos parece ter sido um "laboratório" onde as pesquisas do De prospectiva pingendi foram confrontadas com a execução dos afrescos. Eu daria como argumento que é preciso uma forte motivação para fazer os traços complexos da cabeça do De prospectiva pingendi”' (Clergeau, in Emiliani, Curzi,1996,p.71).

Buscando a aproximação entre a teoria e a prática do pintor, a autora destaca várias partes onde a relação entre os desenhos do tratado e a posição das cabeças nos afrescos coincidem. Nesse sentido, por exemplo, a autora destaca a relação entre a necessidade técnica da execução dos afrescos, e o uso dos cartons, em que o desenho a ser transportado para a parede é demarcado com pontos, perfurando o papel utilizado para a 
execução do desenho inicial. Estes pontos perfurados deveriam seguir as indicações matemáticas presentes no tratado, e também facilitariam o trabalho de ajudantes envolvidos na empreitada. Em busca das possibilidades de aproximação, Clergeau cita um possível auto-retrato do pintor em posição pouco confortável para a observação direta do próprio rosto, presente na Ressurreição, da Pinacoteca de Sansepolcro, (anterior a 1474), indicando, neste momento, uma proximidade entre um desenho do tratado e a cabeça do pintor nesta obra, mas, aqui, a pintura não obedece precisamente à inclinação que havia no tratado, apresentando uma tensão muscular e uma vivacidade que o desenho esquemático do tratado não comportava. "Por maior a ajuda que o tratado pôde trazer à exatidão das reduções, nós encontramos aqui uma musculatura mais viva e não mais uma forma "abstrata". O De prospectiva pingendi foi transcendido"( Clergeau, in Emiliani, Curzi,1996, p.72).

Para Clergeau a motivação maior do tratado é de aprender a ver, construindo a forma a partir de um novo sistema de ou de "uma nova inteligência da forma"(Ibid.p.72). A fase posterior ao tratado seria de maior liberdade e de construções menos sistemáticas. A autora não se detém em tentar entender melhor o que seria este aprender a ver, e de que modo este rigor presente nas construções geométricas seriam uma forma do ver.

Aspectos culturais envolvidos nesta relação são sobretudo aqueles ligados ao ensino, e à necessidade do trabalho conjunto, em que algumas funções pudessem ser delegadas a ajudantes ou aprendizes. Quanto ao caráter substancialmente matemático da linguagem do tratado, ultrapassam uma simples necessidade de precisão. Como bem coloca Baxandall em $O$ olhar renascente, pintura e experiência social na Itália da Renascença (1991), a matemática era uma espécie de gramática da época, principalmente ligada às relações comerciais que envolviam complicados cálculos de volume, área, entre outros, presentes em todas as transações. Um dos exemplos privilegiados de Baxandall nesta obra são justamente os textos de Piero della Francesca e sua complicada matemática dirigida aos que necessitavam calcular precisamente volumes complexos como barris, como o tratado $D e$ abaco, que ensinava matemática a comerciantes. (Baxandall,1991,p.168).

Afirma Baxandall: "A capacidade que Piero ou qualquer outro pintor usava para analisar as formas que pintava eram as mesmas que Piero ou qualquer comerciante usava para medir quantidades (...) E a associação entre a técnica de medir e a pintura, que o próprio Piero personifica, é extremamente concreta. De um lado, muitos pintores, eles próprios homens de negócios, haviam passado pela instrução matemática secundária 
das escolas leigas: essa era a geometria que conheciam e usavam cotidianamente. Por outro lado, o público culto tinha essas mesmas noções geométricas para apreciar uma pintura: era um instrumento do qual eram dotados para expressar suas opiniões, e os pintores sabiam disso" (Baxandall, Ibid. p.169).

O uso, por exemplo, de uma tenda no Sonho de Constantino, é uma forma próxima de algo que era visualmente muito similar a um cone e um cilindro e fazia parte de um repertório de elementos visuais cotidianos, utilizados para o comércio, e o "resultado era um conhecimento mais completo da tenda enquanto volume e forma particular. Não há nada de banal no uso que Piero faz aqui da capacidade de seu público; é um modo de satisfazer à terceira exigência da Igreja ao pintor, que era a de se servir da virtude particular da proximidade e da força do sentido visual" (Baxandall, p.170). A inclinação da melhor forma, aquela que pode ser mais facilmente vista, é bem vinda à relação entre a pintura e o poder de "dar a ver melhor" que emana das formas geométricas. Desta maneira, fica mais claro em que sentido o tratado pode estar relacionado a uma necessidade de aprender a ver, como colocado por Clergeau. Mas, este aprender a ver está mais próximo de uma tomada do mundo a partir de elementos decifráveis pela geometria que habita a sensibilidade da época, como bem coloca Baxandall.

De prospectiva pingendi parece se dirigir aos que necessitavam, então, tornar a visibilidade mais "clara", retirar dela as qualidades essencialmente decifráveis e para isto precisavam desenhar com precisão e com commensuratio, ou seja, com as coisas proporcionalmente colocadas em seus devidos lugares. Os exemplos de Piero della Francesca são sobretudo dirigidos a objetos pequenos, e proporções restritas a determinados espaços arquitetônicos. A qualidade essencialmente pingendi, a cor, não cabe neste tipo de tratado, apesar de Piero incluí-la entre as partes essenciais da pintura. Pois, como tratar da cor em um escrito que trata de projeções geométricas de corpos sólidos? Esta é uma questão que se aproxima da análise de Merleau-Ponty em $O$ olho e o espirito $(1984,1960)$, onde retoma a Dióptrica de Descartes, e analisa de que forma Descartes pôde tratar o poder da pintura essencialmente através do desenho e da perspectiva geométrica, não imputando à cor nenhum valor além deste de preenchimento decorativo de superfícies. "Descartes privilegiou a gravura, pois está mais próxima do desenho, que opera com linhas que representam as coisas em sua extensão, o que define propriamente a sua existência. Ou seja, uma vez que a representação verdadeira das coisas restringe-se à forma de sua extensão, Descartes destaca as linhas que definem o contorno das coisas, e 
o método da perspectiva, que é a possibilidade de sua representação no espaço. Descartes ignora, portanto, o valor da cor na pintura e o considera decorativo" (Furlan, Rozestraten, 2005,p.69).

$\mathrm{E}$, no entanto, em Breve mas verídica história da pintura italiana (1980,2005), Roberto Longhi revela a suma importância da obra de Piero della Francesca para o desenvolvimento da espacialidade na pintura do quatrocentos italiano, e atribui a este pintor a capacidade de ter realizado em suas pinturas a máxima condensação de elementos pictóricos que unem forma, espaço e cor, dando a esta poderosa síntese a denominação "síntese perspectiva de forma e cor", assumindo o máximo do poder da superfície, com a cor, e igualmente o máximo do poder da profundidade, com a forma.

A cor e a qualidade luminosa da pintura de Piero são as qualidades mais essencialmente destacadas por Roberto Longhi, em Piero della Francesca, $(1927,1989)$. Nesta obra, Longhi aponta, diversas vezes, para uma relação de proximidade entre a forma e o pensamento matemático, onde podemos perceber, grosso modo, duas formas de aproximação: uma em que predomina a semelhança da forma pintada com o rigor de formas geométricas, e, outra em que a forma parece derivar de uma geometria que lhe é anterior.

Vejamos algumas passagens dos comentários de Roberto Longhi.

No Batismo de Cristo, para o homem, que em uma posição pouco comum, aparece se despindo ao fundo, a relação que Longhi estabelece é com um harmonioso "bloco de gesso", acrescentando a esta figura a expressão "homo quadratus" (1989, p.32), que tomaria entre seus limites enrijecidos, o rio sob os pés e as figuras dos orientais ainda mais ao fundo.

Nos três corpos dos anjos as relações entre formas geométricas e formas pintadas são em dois sentidos. Primeiro, em suas cabeças há simples coroas que Longhi relaciona com a forma do círculo, ou, "a verdadeira guirlanda aqui oferece uma verdade concreta à definição do círculo" (Longhi,1989, p.32). Segundo, entre os corpos revestidos de tecidos que "caem e são naturais", tão naturais como são as caneluras das colunas, e, portanto, fica evidente um determinado endurecimento que dá a estes corpos o aspecto das mesmas. Longhi aponta, ainda, uma particular relação entre a árvore no primeiro plano e as figuras, permeando esta relação a densidade destes corpos que parecem se fincar na terra, afirmando que a árvore "na maneira que ela tem de se colocar, tem um ar quase humano, com a brancura de seu tronco e sua rica folhagem ritmada" (1989, p.32,). 
Nos escritos dedicados ao Poliptico da Misericórdia, Longhi descreve as figuras de São Sebastião e São João Batista como "dois blocos monolíticos, abruptos, cruelmente revelados pela luz"(p.38).

Nos retratos do casal Federico da Montefeltro e Battista Sforza a linearidade que mais facilmente seria proposta pelo perfil das cabeças é desconsiderada em favor de uma forma estrutural, ou como escreve Longhi, de um "senso estrutural de formas regulares no próprio Federico, na escolha do barrete redondo, nos planos do rosto" (2005,p.84). Para a cabeça de Batista Sforza o adjetivo escolhido por Longhi é igualmente geometrizante, "cabeça de esférica".

Segundo Longhi, uma cabeça comparável a um "polígono igualmente dividido entre o claro do rosto e o marrom da cabeleira" (1989, p.57), é a forma de Malatesta no afresco de Rimini, polígono que se liga a uma massa "isósceles de seu mantelete de damasco", que "cai como um simples teorema de Euclides"(Ibid., p.60).

No Encontro de Salomão e a rainha de Sabá, o homem com o manto sobre o ombro e a mulher à sua frente com a mão sobre a cintura formam, segundo Longhi, as arestas de um cubo invisível (Ibid., p.75).

“(...) perguntamos se, no fundo da operação pictural de Piero, não havia um exercitium geometriae occultum nescientis se mensurare animi", traduzido, segundo a edição francesa, como "um exercício oculto de geometria feito por um espírito que não sabe se medir" (Longhi, Ibid.p.69).

"Diferentemente da arte dita de inspiração, que, partindo de um impulso, tende a verificá-la em seguida por uma fria revisão de estilo, a criação parece, em Piero, seguir uma via oposta: à maneira de um esboço, ela coloca um teorema, que vem em seguida se revestir docemente e como que se abrandar na apreciação de um espetáculo. Da mesma maneira que Leonardo via as figuras nas manchas das paredes, ou melhor, ao contrário de Leonardo, Piero via-os inicialmente em estruturas mudas de teoremas euclidianos" (Longhi, Ibid.,p.69).

Nos comentário de Longhi percebemos os dois aspectos das aproximações entre a forma pictórica e o pensamento matemático que a permeia, uma aproximação da forma a uma forma geométrica, por exemplo, o quadrado para o homem que se despe e o círculo para as guirlandas, e na aproximação da forma com outra forma, a relação tronco, figuras humanas, no Batismo de Cristo. Sobre esta obra, o autor afirma que todo o seu conjunto aparece com uma admirável nitidez e um cromatismo primoroso que, segundo Longhi, é resultante do trabalho do "um conjunto divinamente contemplado pelo olho da perspectiva" (Ibid., p.33). 
Interessante é que Longhi não se refere ao tratado, a não ser para incluí-lo na biografia ao final de seu livro, comentando tratar-se de um tratado quase "puramente matemático" (Ibid., p.201). Não há, portanto, em Longhi nenhum interesse em comentar a obra de Piero a partir dos escritos do pintor. Mas há uma relação com a geometria sempre relacionada à obra pictórica de Piero e, muito provavelmente, ao entusiasmo de Longhi com a arte futurista italiana.

A obra de Eugenio Battisti, Piero della Francesca é mais enfática na apresentação de uma relação menos direta entre os escritos matemáticos de Piero e suas pinturas. O que de fato podemos observar é uma constante preocupação do autor em perceber que as ordenações geométricas de Piero são desobedientes e visam, em muitos momentos, mais a uma aproximação com o espaço percebido do que com a representação deste espaço através da perspectiva geométrica.

Battisti aponta certo declínio da presença da força da perspectiva nas obras de Piero, e uma forte relação do pintor com a experiência visual. O que chama atenção no texto de Battisti é a precisão das análises entre a pintura e a relação com a perspectiva. Há, na sua pesquisa e de seus alunos, o interesse de reconstituir em perspectiva os espaços das pinturas de Piero, e compará-los com a mesma. Ora, o que se nota, quase sempre, é o desajuste que existe entre o espaço efetivamente pintado e o espaço que seria pintado se as leis da perspectiva fossem aplicadas rigorosamente. Isto acontece, evidentemente, com maior ênfase nas arquiteturas, que podem ser reconstituídas, e não com paisagens. A análise das paisagens, por sua vez, leva a perceber a forte relação da memória paisagística de Piero, pois a relação privilegiada em suas paisagens é com sua cidade natal, Borgo San Sepulcro. (Battisti, 1971, p.16)

De maneira mais ampla, afirma Battisti, a geometria encontrada na pintura de Piero não funciona como uma medida anterior à obra, ao contrário, funcionariam, as duas, pintura e matemática, dentro de uma lógica compositiva (Ibid., p.14). No Políptico de Perugia, Battisti afirma tratarse de um abandono das investigações perspécticas e de um privilégio dos espaços vazios, que, no entanto, são tão bem colocados proporcionalmente aos espaços que as figuras ocupam, que revelam a presença da capacidade compositiva derivada de um pensamento matemático: "De Piero, amante das formas precisas resta apenas a extraordinária capacidade de criar relações mediante a presença do vazio, de modelar rostos regulares e arejadamente destacados do fundo, ainda mais sendo este um ofuscante damasco de ouro". (Ibid., p.436). 
Battisti coloca este declínio do respaldo fornecido pela ordenação da perspectiva como um caminho, mais ao final da carreira de Piero, de superação da fase anterior: "podemos dizer que a crise foi não apenas um fato de evolução estilística, mas alguma coisa mais profunda, isto é um afastamento da confiança absoluta no cálculo e na projeção abstrata, o motivo, talvez, de um ceticismo, sempre mais corrosivo, sobre a coincidência entre as leis racionais e as estética" (Ibid., p.420).

A passagem pelo estudo da perspectiva talvez se deva mais ao interesse pela matemática, embora, neste período, para qualquer pintor ela fosse obrigatória. Mas em Piero, segundo a análise de Battisti, as duas investigações acabam se distanciando e, ao que parece, para que a pintura seguisse construções menos comprometidas com as rigorosas leis matemáticas (Ibid., p.420).

Em uma direção que tende mais para a aproximação com um espaço percebido com o espaço pictórico, Carlo Bertelli em Piero della Francesca, la forza divina della pintura (1991), destaca uma frase de Piero della Francesca, onde o pintor escreve sobre a falta de clareza da percepção quando se aproxima do fim de certa inscrição visual: “O intelecto não percebe nem compreende as suas partes senão como una mancha vista a grande distância, que não sabe julgar se é homem ou outro animal" (della Francesca Apud. Bertelli, 1991, p.151). Bertelli recupera a observação de Damish (citar), de que esta consideração leva em conta menos os aspectos fisiológicos do que os aspectos da construção pictórica, quando leva aos extremos a tomada segundo as leis da perspectiva. Ou seja, esta seria uma observação que se origina muito mais da projeção geométrica da perspectiva do que da ótica (Ibid., p.151). Assim, esta zona confusa ficaria fora de uma determinada rede ou quadriculado criado pela projeção geométrica e não fora do campo de visão que depende do movimento dos olhos e de todo o corpo. Bertelli afirma que o pintor elege algum ponto privilegiado da visão.

Daniel Arasse, Piero della Francesca e la perspective du peintre, apoia-se na posição de Eugenio Battisti e aponta, também para uma divergência entre a prática artística de Piero e seus escritos, nestes um trabalho de explicitação dos princípios matemáticos que orientam a projeção em perspectiva, na obra uma subversão destes princípios através do modo como utiliza a cor e a luz. $\mathrm{Na}$ Invenção da verdadeira Cruz em Arezzo, o branco da fachada e o da base da torre à distância aproxima-as, assim como o vermelho colocado sobre uma fachada próxima e outra vista ao longe, e um outro branco aproxima uma cúpula longínqua das laterais do templo 
mais próximo. Portanto, é através da cor, e da equivalência luminosa, que Piero aproxima planos distantes.

\section{Discussão final}

Percebemos ao longo desses comentários que há na pintura de Piero della Francesca um descolamento da frieza matemática que aparece em seu tratado sobre perspectiva na pintura. Existe, sem dúvida, um rigor formal, e a supressão de gestos expontâneos e enredos anedóticos; tudo parece tão estático e singularmente equilibrado, mas seriam estas características que denunciariam por trás do pintor o matemático calculista? Tentamos articular idéias que apontam para uma direção contrária a esta, pois na pintura de Piero, algumas extremamente devedoras da ordenações da perspectiva geométrica, a mesma não se coloca sempre como regra. Muitas vezes há a subversão total dos princípios da perspectiva, especialmente nas paisagens abertas, e, como em poucos pintores, a cor, esta qualidade não mensurável da pintura, aparece com uma força admirável. Além desta, a segunda qualidade, extremamente pictórica de Piero, é a luz, que atinge aqui um dos seus maiores momentos da história da pintura.

\section{Bibliografia}

Battisti, E. 1971, Piero della Francesca, Ins.Editoriale Italiano,Milão.

Baxandall, M. 1991, O olhar renascente, pintura e experiência social na Itália da Renascença, Paz e Terra, São Paulo.

Bertelli, C. 1991, Piero della Francesca, La forza divina della pintura, Almicare Pizzi editore.

Clergeau, M.F. 1996, Du De prospectiva pingendi à la peinture de Piero: Quel lien?, Emiliani e Curzi (org.), in Piero della Francesca tra arte e scienza, Marsilio Editori, Veneza.

Furlan, R. / Rozestraten, A. S. 2005, Arte em Merleau-Ponty, in Natureza Humana - Revista Internacional de Filosofia e Práticas Psicoterápicas, vol.7. n.1. P.59-93.Educ.

Longhi, R. 1980, Piero della Francesca, Hazan, Paris.

della Francesca, P. 1998, De la perspectiva en Peinture, In Media Res, Paris. 